\title{
Body Mass Index and Musculoskeletal Pain: A Cross-Sectional Study
}

\author{
Susana Rosa ${ }^{1}$, Diogo Martins ${ }^{1}$, Mariana Martins ${ }^{1}$, Bruno Guimarães ${ }^{2}$, Leonor Cabral ${ }^{1}$, Luís Horta ${ }^{1}$ \\ 1. Physical Medicine and Rehabilitation, Centro Hospitalar Universitário de Lisboa Central, Lisbon, PRT 2. Physical \\ Medicine and Rehabilitation, Central Entre o Douro e Vouga Hospital, Santa Maria da Feira, PRT
}

Corresponding author: Susana Rosa, susanafrosa@gmail.com

\section{Abstract \\ Introduction}

With obesity reaching pandemic proportions, its detrimental influence on many health-related conditions has recently become a focus of research. Musculoskeletal (MSK) pain is one of several disorders associated with obesity.

\section{Materials and methods}

This study was designed to identify MSK pain in individuals with severe obesity, recruited from a specialized obesity clinic, and to evaluate the correlation between the MSK symptoms and some individual criteria.

\section{Results}

In 466 patients ( 342 females and 124 males), with a mean BMI of $42,77 \pm 5.64 \mathrm{~kg} / \mathrm{m}^{2}, 90,3 \%$ reported MSK pain. Severe pain was reported by $57,8 \%$ of female $v s 26,6 \%$ of male patients. Female patients showed higher mean pain level when compared with males. Body sites with a higher prevalence of pain were: knee (63.5\%), lumbar region (46.8\%), hip (29\%) and ankle (23\%), with a predominance of severe pain. BMI have shown a positive correlation to numeric rating scale score in female participants in three body regions: shoulder $(\mathrm{P}=$ $0.010)$, knee $(P=0.042)$ and ankle $(P=0.024)$. Body sites with higher pain prevalence were especially in areas of increased mechanical load.

\section{Conclusions}

Understanding the relationship between obesity and pain may provide insights into preventive measures and therapeutic strategies for MSK pain. Persistent MSK pain is a significant problem in obese patients that can have a negative relationship with quality of life and function. This fact highlights the importance that patients with obesity may have access to interdisciplinary care, for the prevention and rehabilitation of MSK disorders. To further understand this association, more robust studies are needed.

Review began 02/09/2021 Review ended 02/13/2021 Published 02/17/2021

\section{() Copyright 2021}

Rosa et al. This is an open access article distributed under the terms of the Creative Commons Attribution License CC-BY 4.0., which permits unrestricted use, distribution, and reproduction in any medium, provided the original author and source are credited.
Categories: Pain Management, Preventive Medicine, Epidemiology/Public Health Keywords: obesity, musculoskeletal, pain, morbid obesity

\section{Introduction}

Obesity is yet a neglected public health concern. It is a chronic disease, with multifactorial genesis, requiring concerted efforts, posing as an important risk factor for the development and deterioration of another diseases [1]. Worldwide obesity has nearly tripled since 1975. In 2016, more than 1.9 billion adults were overweight. Of these, over 650 million were obese [2].

In 2015, the National Institute of Health Doutor Ricardo Jorge conducted a study that described the prevalence of overweight and obesity in the Portuguese population, verifying that $38.9 \%$ of the adults (25-74 years) living in Portugal was overweight and $28.7 \%$ suffered from obesity. The prevalence of overweight was higher in men (45.4\%), while the prevalence of obesity was higher in women (32.1\%) [3].

MSK pain is one of several disorders associated with obesity [4]. Mechanisms linking obesity and pain are complex and include behavioral, mechanical, biological and genetic factors. Pain affecting weight-bearing joints such as the knee, ankle and foot, as well as back pain, are among the most frequent complaints, often reported together as multisite pain [5,6]. Excessive weight increases mechanical stress to the joints and tissues of the body [7] and induces physical limitations and bodily pain. Self-reported bodily pain symptoms increase with progressively higher body mass index (BMI) values [8].

Reported risk factors for MSK pain include older age, female gender, high occupational workload and low physical activity [9-12]. Obesity is also closely related to MSK pain and physical dysfunction [13,14]. Specifically, increasing severity of pain is observed at higher BMI classifications $[15,16]$. 


\section{Cureus}

The authors collected and detailed all the data of a sample of individuals with morbid obesity followed in an obesity and metabolic diseases unit. Additionally, the MSK pain was investigated in this group of patients, to evaluate the relationship between BMI and MSK pain.

\section{Materials And Methods}

The authors conducted a cross-sectional study (data collected between 2017 and 2018). The patients were recruited from a specialized Obesity Clinic, named "Surgical Treatment Unit for Obesity and Metabolic Diseases” (englobing different medical and surgical specialties such as General Surgery; Internal Medicine; Endocrinology; Anesthesiology; Nutrition; Clinical Psychology; Physical Medicine and Rehabilitation; Gastroenterology; Plastic Surgery). All the participants were informed about the study, and verbal informed consent was obtained.

All the patients involved in the obesity and metabolic diseases program were enrolled in this study. The inclusion criteria for entering the obesity program were the following: age superior to 18 years; $\mathrm{BMI} \geqslant$ $35 \mathrm{Kg} / \mathrm{m}^{2}$ with comorbidities or $\geqslant 40 \mathrm{Kg} / \mathrm{m}^{2}$ without comorbidities; more than two years of obesity-resistant to conservative medical treatment and educational/behavioral intervention.

Participants completed a Clinical Questionnaire to characterize their pain complaints regarding multiple musculoskeletal locations, characterizing the anatomic location and pain intensity in the last three months.

The population in the study was characterized namely regarding personal feature (gender, age and body mass index) and their pain complaints.

The patients completed a questionnaire referring the numeric rating scale [17] regarding pain in the following seven anatomical regions: hand \& wrist, shoulder, lumbar region, hip, knee, ankle and foot. The authors considered the overall score pain to be equivalent to the highest reported pain per region by the patient, experienced in the last three months. The numeric rating scale, ranging from 0 to 10 , was used to assess pain intensity in the seven anatomical regions. All the assessments reported were pre-surgery.

Statistical analysis was done using the Statistical Package for Social Sciences (SPSS), version 25.0 (IBM Corp., Armonk, NY). Statistical significance was determined at the level of $\mathrm{P}<0.05$. In order to assess the normal distribution of the continuous variables, Shapiro-Wilk Test was conducted. Spearman's correlation coefficient (rho) was used to assess the correlation between the body mass index score and the level of pain per region. Cohen's standard was used to analyze the correlation coefficients regarding the strength of the relationship [18].

\section{Results}

A total of 466 (342 female (73.4\%)) patients were analyzed. The mean age was $46.28 \pm 10.59$ years (female: $46.01 \pm 10.59$; male: $47.02 \pm 10.61$ ). The mean participants BMI was $42.77 \pm 5.64 \mathrm{~kg} / \mathrm{m}^{2}$ (females: $42.52 \pm$ 10.51; males: $43.44 \pm 5.94$ ), as shown in Table 1 .

\begin{tabular}{|l|l|}
\hline Variable & Group (N=466) \\
\hline Female Gender, N (\%) & $342(73.4)$ \\
\hline Age in years, mean (SD) & $46.28(10.59)$ \\
\hline BMl in $\mathrm{kg} / \mathrm{m}^{2}$, mean (SD) & $42.77(5.64)$ \\
\hline Female (SD) & $42.52(10.51)$ \\
\hline Male (SD) & $43.44(5.94)$ \\
\hline
\end{tabular}

TABLE 1: Characteristics of participants.

\section{Level of pain by gender}

The overall prevalence of pain was $90,3 \%$, female $95 \%$ vs male $77,4 \%(\mathrm{P}<0,001)$. Severe pain was reported by $57,8 \%$ of female vs $26,6 \%$ of male participants (Figure 1 ). 


\section{Cureus}

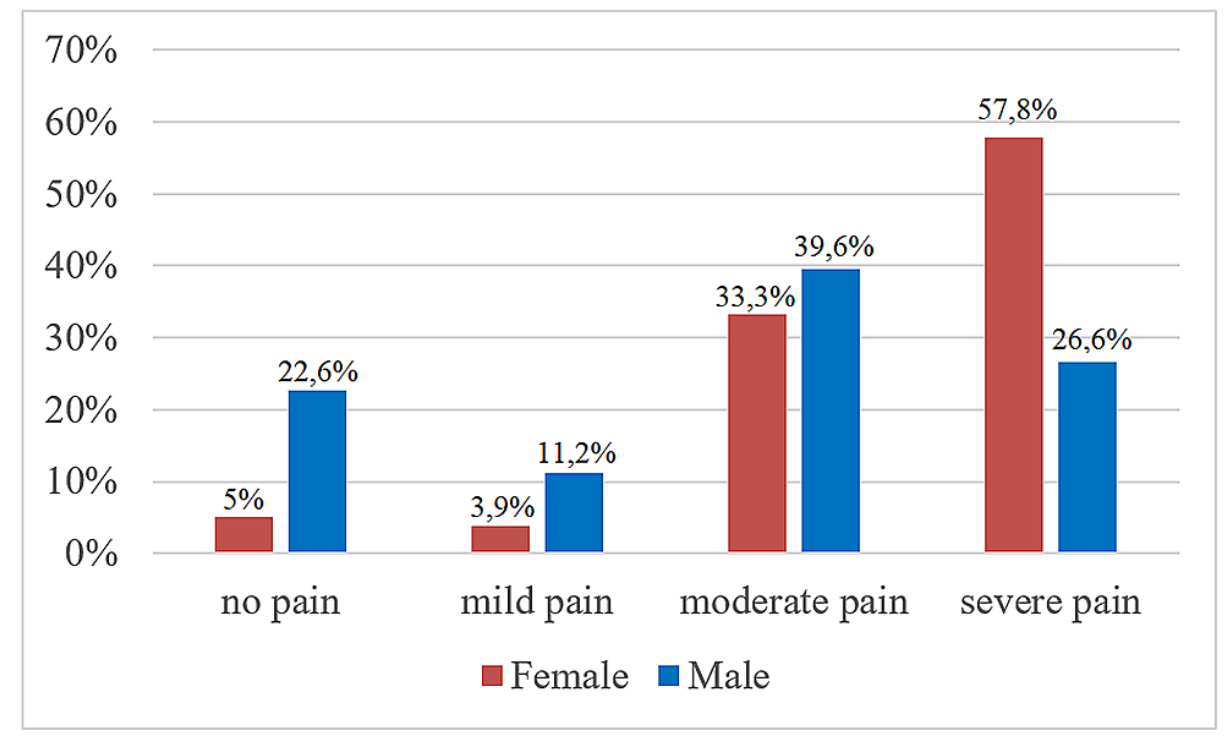

FIGURE 1: Prevalence and intensity of pain by gender.

Female participants showed a higher mean pain level when compared with male participants (female $6.57 \pm$ 2.38 vs male $4.34 \pm 2.89)(\mathrm{P}<0,001)$.

\section{Prevalence of pain by body region}

The prevalence of pain by body region were: hand \& wrist $10.5 \%(\mathrm{~N}=49)$, shoulder $15.7 \%(\mathrm{~N}=73)$, lumbar region $46.8 \%(\mathrm{~N}=218)$, hip $29 \%(\mathrm{~N}=135)$, knee $63.5 \%(\mathrm{~N}=295)$, ankle $23 \%(\mathrm{~N}=107)$ and foot $12.4 \%(\mathrm{~N}=58)$.

\section{Correlation between pain by body region and BMI}

BMI showed a moderate positive correlation to the numeric rating scale score in female participants in three body regions: shoulder $(\mathrm{rho}=0.440, \mathrm{P}=0.010)$, knee $(\mathrm{rho}=0.410, \mathrm{P}=0.042)$ and ankle $(\mathrm{rho}=0.422, \mathrm{P}=$ 0.024 ). No statistically significant associations were found in other body regions in both female and male patients, as presented in Table 2.

\begin{tabular}{|c|c|c|c|c|}
\hline & \multicolumn{4}{|l|}{ Body mass index (BMI) } \\
\hline & \multicolumn{2}{|l|}{ Female } & \multicolumn{2}{|l|}{ Male } \\
\hline & Spearman correlation & $P$ & Spearman correlation & $P$ \\
\hline Hand \& wrist & 0.016 & 0.769 & 0.068 & 0.455 \\
\hline Shoulder & 0.440 & 0.010 & 0.005 & 0.959 \\
\hline Lumbar region & 0.004 & 0.942 & 0.040 & 0.660 \\
\hline Hip & 0.052 & 0.336 & 0.089 & 0.328 \\
\hline Knee & 0.410 & 0.042 & 0.013 & 0.888 \\
\hline Ankle & 0.422 & 0.024 & 0.057 & 0.533 \\
\hline Foot & 0.023 & 0.677 & 0.123 & 0.174 \\
\hline
\end{tabular}

TABLE 2: Correlation coefficients between pain by body region and BMI.

\section{Discussion}

Results from the current study showed a high MSK pain prevalence among the subjects $(90,3 \%)$, more in females. An even higher prevalence was found in another study, in which $100 \%$ of the obese individuals evaluated during preoperative bariatric surgery reported MSK pain in at least one region of the body $[19,20]$. 
Body sites with a higher prevalence of pain were seen especially in areas of increased mechanical load: knee (63.5\%), lumbar region (46.8\%), hip (29\%) and ankle (23\%), with a predominance of severe pain. Larsson's results showed that obese women had more MSK pain in the lower back, knee and foot [21]. A meta-analysis published in 2010 showed that obesity was strongly associated with an increased need for health care, for the treatment of acute and chronic lower back pain [22].

Female participants have reported more pain and a higher prevalence of moderate and intense pain when compared to male participants, as described by other studies reporting that female sex and obesity were factors significantly associated with the persistence or development of MSK pain [23,24], and with higher intensity [25].

Increased BMI ratio was significantly associated with MSK pain among women in shoulder, knee and ankle. It has been demonstrated that overweight is associated with adverse effects on the knees and feet, such as pain, stiffness and functional changes [26,27]. To provide preventive measures and therapeutic interventions for MSK pain, it is crucial to understand the relationship between obesity and pain. The proinflammatory effect of obesity in the pathogenesis of MSK diseases, independent of its biomechanical effect, has also been gaining interest [28]. A systematic review has shown a dose-response relationship between BMI and incident shoulder pain: overweight was associated with an increase of inflammatory factors, which could therefore be related to the development of shoulder disorders [29].

One of the limitations of this study is that the sample selection can contribute to an overestimation of the individuals' probability of presenting MSK pain, since it is a population with a very high BMI. It is important to acknowledge that severe obesity increases the risk of developing MSK disorders [30].

The study remains ongoing - follow-up after bariatric surgery - to infer whether the expected weight loss is followed by a proportional decrease in pain complaints.

\section{Conclusions}

In conclusion, the authors found a high prevalence of MSK pain and intense pain among the patients, especially in the knee and lumbar regions. Persistent MSK pain is a significant problem in obese patients that can have a negative impact on the quality of life and function. This fact highlights the importance that obese subjects may adopt a preventive healthcare and may have access to an interdisciplinary care, to ensure a more effective intervention and rehabilitation, preventing MSK disorders. More robust studies are needed to detail and further investigate these associations.

\section{Additional Information \\ Disclosures}

Human subjects: Consent was obtained or waived by all participants in this study. Animal subjects: All authors have confirmed that this study did not involve animal subjects or tissue. Conflicts of interest: In compliance with the ICMJE uniform disclosure form, all authors declare the following: Payment/services info: All authors have declared that no financial support was received from any organization for the submitted work. Financial relationships: All authors have declared that they have no financial relationships at present or within the previous three years with any organizations that might have an interest in the submitted work. Other relationships: All authors have declared that there are no other relationships or activities that could appear to have influenced the submitted work.

\section{References}

1. Direção-Geral da Saúde. A obesidade como doença crónica . (2020). https://www.dgs.pt/doencas-cronicas/aobesidade.aspx.

2. World Heath Organization. Obesity and Overweight. (2020). https://www.who.int/news-room/factsheets/detail/obesity-and-overweight.

3. Gaio V, Antunes L, Barreto M, et al.: Prevalence of overweight and obesity in Portugal: results from the first Portuguese Health Examination Survey (INSEF 2015). Obes Res Clin Pract. 2017, 12:40-50. 10.1016/j.orcp.2017.08.002

4. Kortt M, Baldry J: The association between musculoskeletal disorders and obesity. Aust Health Rev. 2002, 25:207-214. 10.1071/ah020207

5. Brady SRE, Hussain SM, Brown WJ, et al.: Predictors of back pain in middle-aged women: data from the Australian longitudinal study of women's health. Arthritis Care Res. 2017, 69:709-716. 10.1002/acr.22982

6. Frilander H, Solovieva S, Mutanen P, et al.: Role of overweight and obesity in low back disorders among men: a longitudinal study with a life course approach. BMJ Open. 2015, 5:e007805. 10.1136/bmjopen-2015007805

7. Vincent KR, Vincent HK: Resistance exercise for knee osteoarthritis. PM R. 2012, 4:S45-S52. 10.1016/j.pmrj.2012.01.019

8. Andersen RE, Crespo CJ, Bartlett SJ, Bathon JM, Fontaine KR: Relationship between body weight gain and significant knee, hip, and back pain in older Americans. Obes Res. 2003, 11:1159-1162. 10.1038/oby.2003.159

9. Cho NH, Kim I, Lim SH, Kim HA: Prevalence of widespread pain and its influence on quality of life: 
population study in Korea. J Korean Med Sci. 2012, 27:16-21. 10.3346/jkms.2012.27.1.16

10. Mourao AF, Blyth FM, Branco JC: Generalised musculoskeletal pain syndromes. Best Pract Res Clin Rheumatol. 2010, 24:829-840. 10.1016/j.berh.2010.10.005

11. Karsh BT: Theories of work-related musculoskeletal disorders: implications for ergonomic interventions . Theor Issues Ergonomics Sci. 2006, 7:71-88. 10.1080/14639220512331335160

12. Haukka E, Ojajarvi A, Takala EP, Viikari-Juntura E, Leino-Arjas P: Physical workload, leisure-time physical activity, obesity and smoking as predictors of multisite musculoskeletal pain: a 2-year prospective study of kitchen workers. Occup Environ Med. 2012, 69:485-492. 10.1136/oemed-2011-100453

13. Peltonen M, Lindroos AK, Torgerson JS: Musculoskeletal pain in the obese: a comparison with a general population and long-term changes after conventional and surgical obesity treatment. Pain. 2003, 104:549557. 10.1016/S0304-3959(03)00091-5

14. Bingefors K, Isacson D: Epidemiology, co-morbidity, and impact on health-related quality of life of selfreported headache and musculoskeletal pain-a gender perspective. Eur J Pain. 2004, 8:435-450. 10.1016/i.ejpain.2004.01.005

15. Hitt HC, McMillen RC, Thornton-Neaves T, Koch K, Cosby AG: Comorbidity of obesity and pain in a general population: results from the Southern Pain Prevalence Study. J Pain. 2007, 8:430-436. 10.1016/j.jpain.2006.12.003

16. Stone AA, Broderick JE: Obesity and pain are associated in the United States . Obesity. 2012, 20:1491-1495. 10.1038/oby.2011.397

17. Boonstra AM, Stewart RE, Koke AJ, et al.: Cut-off points for mild, moderate, and severe pain on the numeric rating scale for pain in patients with chronic musculoskeletal pain: variability and influence of sex and catastrophizing. Front Psychol. 2016, 7:1466-1485. 10.3389/fpsyg.2016.01466

18. Guimarães B, Machado JF, Tsisar S, et al.: The role of anatomy computer-assisted learning on spatial abilities of medical students. Anat Sci Educ. 2019, 12:138-153. 10.1002/ase.1795

19. Hooper MM, Stellato TA, Hallowell PT, Seitz BA, Moskowitz RW: Musculoskeletal findings in obese subjects before and after weight loss following bariatric surgery. Int J Obes. 2007, 31:114-120. 10.1038/sj.ijo.0803349

20. Calenzani G, Santos FF, Wittmer VL, Freitas GK, Paro F: Prevalence of musculoskeletal symptoms in obese patients candidates for bariatric surgery and its impact on health related quality of life. Arch Endocrinol Metab. 2017, 61:319-325. 10.1590/2359-3997000000237

21. Larsson UE: Influence of weight loss on pain, perceived disability and observed functional limitations in obese women. Int J Obes. 2004, 28:269-277. 10.1038/sj.ijo.0802534

22. Shiri R, Karppinen J, Leino-arjas P, Solovieva S, Viikari-juntura E: The association between obesity and low back pain: a meta-analysis. Am J Epidemiol. 2010, 171:135-154. 10.1093/aje/kwp356

23. Yoo JJ, Cho NH, Lim SH, Kim HA: Relationships between body mass index, fat mass, muscle mass, and musculoskeletal pain in community residents. Arthritis Rheumatol. 2014, 66:3511-3520. 10.1002/art.38861

24. Park IY, Cho NH, Lim SH, Kim HA: Gender-specific associations between fat mass, metabolic syndrome and musculoskeletal pain in community residents: a three-year longitudinal study. PLoS One. 2018, 13:e0200138. 10.1371/journal.pone.0200138

25. Masheb RM, White MA, Grilo CM: Sex differences and correlates of pain in patients with comorbid obesity and binge eating disorder. Eur Eat Disord Rev. 2016, 24:247-250. 10.1002/erv.2432

26. Tanamas SK, Wluka AE, Davies-Tuck M, et al.: Association of weight gain with incident knee pain, stiffness, and functional difficulties: a longitudinal study. Arthritis Care Res. 2013, 65:34-43. 10.1002/acr.21745

27. Walsh TP, Arnold JB, Evans AM, Yaxley A, Damarell RA, Shanahan EM: The association between body fat and musculoskeletal pain: a systematic review and meta-analysis. BMC Musculoskelet Disord. 2018, 19:233. 10.1186/s12891-018-2137-0

28. Wluka AE, Lombard CB, Cicuttini FM: Tackling obesity in knee osteoarthritis. Nat Rev Rheumatol. 2013, 9:225-235. 10.1038/nrrheum.2012.224

29. Viikari-Juntura E, Shiri R, Solovieva S, Karppinen J, Leino-Arjas P: Risk factors of atherosclerosis and shoulder pain - Is there an association? A systematic review. Eur J Pain. 2008, 12:412-426. 10.1016/j.ejpain.2007.08.006

30. Faghri PD, Chin WS, Huedo-Medina TB: The link between musculoskeletal pain, lifestyle behaviors, exercise self-efficacy, and quality of life in overweight and obese individuals. Int J Phys Med Rehabil. 2015, 3:255. $10.4172 / 2329-9096.1000255$ 